\title{
Arsenic Compound
}

National Cancer Institute

\section{Source}

National Cancer Institute. Arsenic Compound. NCI Thesaurus. Code C45557.

A white, odorless, inorg anic substance that contains the semi-metallic element arsenic usually in the 3 and 5-valence state, and emits toxic arsenic fumes when heated to decomposition. Arsenic compounds are primarily used in wood preservation. Exposure to this substance irritates skin and mucous membranes, and can affect the gastrointestinal tract, CNS, cardiovascular system, liver, kidneys and blood. Arsenic compounds are known human carcinogens and are associated with an increased risk of developing lung, skin, bladder, kidney, liver, prostate, digestive tract and colon cancer as well as cancer of the lymphatic and hematopoietic system. ( $\mathrm{NCl05})$ 